Akyüz, M. (2017). Karşılaştırmalı edebiyat açısından Necip Fazıl'ın Yunus Emre tiyatrosu ile Nihat Asyalı'nın Yunus Diye Göründüm tiyatrosunun incelenmesi. Ana Dili Eğitimi Dergisi, 5(4), 880-887.

$\begin{gathered}\text { Ana Dili Eğitimi Dergisi } \\ \text { Journal of Mother Tongue Education } \\ \text { www.anadiliegitimi.com }\end{gathered}$
Geliş/Received: 25.09 .2017 Kabul/Accepted:17.10.2017

\title{
Karşılaştırmalı Edebiyat Açısından Necip Fazıl’ın Yunus Emre Tiyatrosu ile Nihat Asyalı'nın Yunus Diye Göründüm Tiyatrosunun İncelenmesi*
}

\author{
Metin AKYÜZ**
}

\begin{abstract}
Öz
Yunus Emre, tarihi bir şahsiyet olduğu kadar kültürel bir imge olarak da Türk edebiyatı ve fikir hayatında önemli bir yer tutmaktadır. Yunus Emre'yi asırlar öncesinden günümüze taşıyarak kalıcılığını sağlayan iki temel özellikten söz edilebilir: Şiirindeki lirizm ve sahip olduğu felsefe. Yunus Emre'nin şiirleri asırlar boyunca halkın gönlünde muhafaza edilerek günümüze kadar taşınırken, şiirleri metinler arası ilişkiler bağlamında nice yazara ilham kaynağı olmuştur. Sahip olduğu felsefe evrensel düzeyde kabul görmesini sağlamıştır. Yunus Emre'nin hayatı, şiirleri ve felsefesi birçok roman, şiir ve tiyatronun konuları arasında yer almıştır. Bu çalışmada Necip Fazıl Kısakürek'in "Yunus Emre" adlı tiyatrosu ile Nihat Asyalı'nın "Yunus Diye Göründüm" adlı tiyatrosu karşılaştırmalı edebiyat biliminin verileri açısından incelenecektir. İnsanlar ve kültürler arası etkileşim kaçınılmazdır. Karşılaştırmalı edebiyatın özünü de bu etkileşim oluşturmaktadır. Bir eserin ya da yazarın diğer bir eser ve yazar üzerindeki etkilerini incelemek için bir karşılaştırmaya ihtiyaç duyulur. Bu çalışmada da Yunus Emre paydasında iki yazarın eserleri karşılaştırılacaktır. Karşılaştırmalı edebiyat açısından söz konusu tiyatro metinleri incelenmeye değer özellikler taşımaktadır. Her iki yazar da eserlerine kendi dünya görüşlerinin ve sanat anlayışlarının damgalarııı vurmayı başarmışlardır. Aynı konu, dönem ve karakteri işlemelerine rağmen birbirinden farklı dil, anlatım ve kurgu özelliklerine sahip iki özgün eserin meydana getirildiği görülmektedir.
\end{abstract}

Anahtar Sözcükler: karşılaştırmalı edebiyat, tiyatro, Yunus Emre, Necip Fazıl Kısakürek, Nihat Asyalı

\section{The Analysis of Necip Fazıl's Yunus Emre Theatre and Nihat Asyalı's Yunus Diye Göründüm Theatre in Terms of Comparative Literature}

\section{Abstract}

Yunus Emre is not only a historical character but also holds an important place as a cultural symbol of Turkish literature and thought life. Two qualities can be mentioned which convey Yunus Emre from centuries ago to present and make him permanent: The lyricism in his poetry and philosophy. His poems are protected in the heart of people and have been conveyed to present day, and they inspired many writers in the context of intertextuality. His philosophy ensured his acceptance internationally. His life, poems and philosophy are subjects of many novels, poems and theatre works. In this study, the theatre by Necip Fazıl named as Yunus Emre and Nihat Asyalı's Yunus Diye Göründüm are analyzed in terms of comparative literature.

\footnotetext{
* Bu araştırma Atatürk Üniversitesi tarafından düzenlenen “Uluslararası Türk Dili ve Edebiyatı Bilgi Şöleni”nde sözlü bildiri olarak sunulmuştur. Erzurum:12-14 Mayıs 2017

${ }^{* *}$ Yrd. Doç. Dr, Abant İzzet Baysal Üniversitesi, Fen Edebiyat Fakültesi, Türk Dili ve Edebiyatı Bölümü, BOLU. E-Posta:akyuz_m@ibu.edu.tr
} 
Interpersonal and intercultural interaction is inevitable. This interaction forms the core of comparative literature. A comparison is needed to examine the effect of a work or a writer on another work or writer. This study bases on two writers' works with the common ground of Yunus Emre. They have similarities and differences although they were published in different years and focused on the same subject. Therefore, these theatre texts are worth studying in terms of comparative literature. Both of the writers managed to mark their world view and art perception on their works. It is observed that two works have different language, style and fiction qualities, although they focus on the same topic, period and character.

Keywords: comparative literature, theatre, Yunus Emre, Necip Fazıl Kısakürek, Nihat Asyalı

\section{Giriş}

Toplumların, kültürlerin ve dillerin birbirinden etkilenmemesi mümkün değildir. Dünya kültürü tek bir milletin değil, bütün insanlığın bir mirası olarak gittikçe artan, gelişen bir özellik göstermektedir. Her millet kültürel, sanatsal ve bilimsel üretimlerini gerçekleştirirken başka milletlerin üretimlerini etkiler ve onlardan etkilenir. Bu etkileme ve etkilenmelerden yola çıkarak Goethe karşılaştırmalı edebiyat çalışmalarının başlangıcı olan dünya edebiyatı kavramını geliştirmiştir. Goethe'nin dünya edebiyatı düşüncesini Fritz Strich şu şekilde açıklamaktadır: "Uluslararası, karaktersiz, halkçı özelliğini reddeden kozmopolit bir edebiyatı kastetmediğini tam tersine ulusların aynılaşmadan karşılıklı birbirlerini algılayacakları, anlayacak, birbirlerini sevmeseler bile birbirlerine katlanacakları bir edebiyatı kastettiğini yazmaktadır"(Akt.: Göbenli,2005:29).

Toplumların birbirlerini etkilemeleri tarihin ilk çağlarından beri görülebilir. Karşılaştırmalı edebiyat çalışmalarını ortaya çıkaran bazı ön koşulların oluşması gerekmektedir. Goethe'nin dünya edebiyatı fikrinin oluşmasında da bu ön koşulların gerçekleşmiş olması yatmaktadır. Bu dönem, keşiflerin tamamlandığı, sanayi devriminin gerçekleştiği, burjuva sınıfının güçlenip pazarlarını yeryüzüne yaydığı, yeryüzü pazarını kurduğu ve ulaşımın kolaylaştığı bir dönemdir (Aytaç,2009;Kefeli,2000). Auerbach, dünya edebiyatının dünyası olan yer kürenin gittikçe küçüldüğünü ve çeşitliliğini kaybettiğini belirtir. "Dünya edebiyatı yalnızca ortak ve insani olana yaslanmakla kalmayıp, bu çeşitliliğin karşııklı olarak döllenmesine de dayanmaktadır" (Göbenli,2005) diyerek dünya edebiyatı için karşılaştırmalı edebiyat çalışmalarının yapııması gereğini vurgulamaktadır. Çeşitli kültür ve edebiyatların varlığı dünya edebiyatının ön koşuludur. Tek tipleşen bir dünyada dünya edebiyatı hem gerçekleşmiş, hem de yok edilmiş olacaktır.

Karşılaştırmalı edebiyatın tarihi ulusal edebiyatların tarihlerini incelemekle başlamıştır. Ulusal edebiyatın ortak paydasını ise dil oluşturmaktadır. Söz konusu dil ve edebiyat evrensel bir boyuta ulaştığı zaman diğer dil ve edebiyatları etkilemesi kaçınılmazdır.

Karşılaştırmalı edebiyat incelemelerinin ortaya çıkışında uluslararası edebiyatların karşılaştırılması hedeflenirken sonraki süreçte aynı edebiyat içindeki yazarların eserleri de karşılaştırma çalışmalarının kapsamında yer almıştır. Aynı edebiyat içindeki eş zamanlı ve farklı 
Karşılaştırmalı Edebiyat Açısından Necip Fazıl’ın Yunus Emre Tiyatrosu ile Nihat Asyalı'nın Yunus Diye Göründüm Tiyatrosunun İncelenmesi

zamanlı ürünler de karşılaştırmalı edebiyatın inceleme alanında yer almıştır. (Aytaç, 2009:18). Ortak kullanım alanı olan dil, ister istemez edebiyat ürünlerinin üretimi sürecinde de etkilenmelere neden olmaktadır. Yabancı edebiyatlardan önce dil içi etkilenmeler önceliklidir. Sanatta etkilenmeler vardır ve olacaktır. Kopya olmadığı sürece bu bir avantaj olarak görülmelidir.

\section{Yöntem}

Nitel bir çalışma olan bu araştırmada doküman incelemesi yapılmıştır. Doküman incelemesi, hedeflenen olgu veya olgular hakkında bilgi içeren yazılı materyallerin çözümlenmesini kapsar (Yıldırım ve Şimşek, 2011). Edebiyat eserleri incelenirken farklı araçlar kullanılabilmektedir. Bu çalışmada da metne bağı̆ bir inceleme yapılacaktır. Bu yaklaşım edebi eseri bir metin olarak görüp öz ve biçim özellikleri bakımından inceler (Aytaç, 2009:99). Karşılaştırmalı edebiyat çalışmaları en yaygın şekliyle ortak konu ve motif ağırlıklı yapılır. Ortak konular insanlığın ortak paydalarda birleştiği konular olmuştur. Yunus Emre de Türk kültür mirasının en önemli şahsiyetlerinden biri olarak kültürümüz içinde önemli bir yer tutmaktadır. Modern edebiyatımızda da ortak konu olarak sıkça yer aldığı görülmektedir. Ortak konuya sahip olan Necip Fazıl Kısakürek'in Yunus Emre adlı tiyatrosu ile Nihat Asyalı'nın Yunus Diye Göründüm adlı tiyatrosu karşılaştırmalı edebiyatın verileri açısından incelenecektir.

\section{Çözümleme}

Yunus Emre, tarihî bir şahsiyet olduğu kadar kültürel bir imge olarak da Türk edebiyatı ve fikir hayatında önemli bir yer tutmaktadır. Yunus Emre'yi asırlar öncesinden günümüze taşıyarak kalıcılığını sağlayan iki temel özellikten söz edilebilir: Şiirindeki lirizm ve sahip olduğu felsefe. Yunus Emre'nin şiirleri asırlar boyunca halkın gönlünde muhafaza edilerek günümüze kadar taşınırken, şiirleri metinler arası ilişkiler bağlamında nice yazara ilham kaynağı olmuştur. Yunus'un sahip olduğu felsefe onun değerinin uluslararası boyutta da kabul görmesini sağlamıştır. Bu doğrultuda da UNESCO 1991 yılını "Yunus Emre Sevgi Yılı”" ilan etmiştir. Yunus Emre'nin hayatı, şiirleri ve felsefesi birçok roman, şiir ve tiyatronun konuları arasında yer almıştır. Yunus Emre konu olarak günümüzde de hala işlenmeye devam edilmektedir.

Gevrek (2012), Yunus Emre'nin son 25 yılda tiyatronun konuları arasında yer aldığını belirterek Yunus Emre konusunu ele alan 11 tiyatro metni saptar. Ancak çalışması içine katmadığı, kayıt altına alınmayan ve çalışmadan sonra da yazılan daha birçok Yunus Emre tiyatrosu bulunmaktadır. Bu çalışmada Necip Fazıl Kısakürek'in Yunus Emre tiyatrosu ile Nihat Asyalı'nın Yunus Diye Göründüm tiyatrosu incelenmiştir. Bu tiyatrolardan Necip Fazıl’ın yazdığı Yunus Emre 1969 yılında yazıımıştır. Nihat Asyalı ise eserini 1986'da yazmıştır. Necip Fazıl Kısakürek (1904-1983) ile Nihat Asyalı (1934-2011) farklı ideolojilerin yazarları olarak karşımıza çıkmaktadır. İncelemenin bir 
tarafını Türk şiirinin en önemli şairlerinden olan ve tiyatro dâhil hemen hemen her türde eser vermiş olan Necip Fazıl oluşturmaktadır. Diğer tarafta da asıl mesleği savcılık olan ama tiyatronun içinde oyuncu, yönetmen ve yazar olarak emek vermiş, yazmış olduğu Uzundere adlı oyunu ile 1966 yılında Fransa'da düzenlenen tiyatro yarışmasında birincilik ödülü alan Nihat Asyalı oluşturmaktadır. Yazarların farklı ideolojilerde olması doğal olarak farklı bakış açılarıyla kurgulanan metinlerin ortaya çıkmasına neden olmuştur. Tarihi bir şahsiyetten yola çıkarak yazılan bu eserler biyografik özellikler taşıması gerektirdiği halde bu özellikleri göstermemektedir. Bunda öncelikle Yunus Emre'nin belirsizliklerle, bilinmeyenlerle ve söylencelerle dolu yaşamı etkilidir. Diğer tarafta ise onu eserlerinde yaşatmaya çalışan yazarların bakış açılarıyla (ideolojileri) şekillendirmeye çalışmaları, onun tarihi bir şahsiyetten çok kurmaca karaktere dönüşmesine neden olmaktadır. Bu durum incelenen metinlerin özetlenmesiyle daha net olarak ortaya konulacaktır.

\section{Yunus Emre}

Yunus, Horasan'dan gelen "sırma kaftanlı" bir bey oğludur ve mezarlığı olmayan köyü aramaktadır. Moğol istilasından dolayı göç etmektedir. Karşılaştığı bir derviş ölümsüzlüğü içinde araması gerektiğini söyler. Ölüm olmayan köyü bulur. Burası Erenler Köyü’dür. Bu köyde ölüm, mezar, cenaze namazı yoktur. Süresi dolan için dağın ardından bir ses gelir ve çağırılan kişi hemen oraya gider. Dağın ardındaki ses Yunus'u çağırır. Yunus'un dağ yolculuğu başlar. Bu yolculuk engellerle doludur ve bu engelleri tek tek aşar ve mürşidine ulaşır. Yunus, bey oğlu kıllı̆ından Türkmen kılığına bürünerek Tapduk Baba'nın karşııına çıkar. Onu çağıran sesin Tapduk Baba olduğunu anlar. Çilehaneye girer. Çilenin kırkıncı gününde bir kadın sesi duyar. Bu ses kendini Tapduk'un kızı Fatma olarak tanıtır. Oysa nefsidir. Yunus nefsiyle mücadeleye başlar. Galip geldikten sonra Fatma ile evlenir. Dergâha odun taşımaya başlar. Otuz yıl odun taşıyarak olgunlaşır. Tapduk Baba son bir keramet göstererek asasını havaya atar. Asa Yunus'u buluncaya kadar gökte dolaşacaktır. Yunus yirmi yıl sonra şiirlerinden dolayı kâfirlikle suçlanarak mahkemeye çıkarılır. Suçlu bulunduğunda da Tapduk Baba'nın asası gelir onu bulur. Bu olay Yunus'un ermişliğini gösterir. Bir süre de asayla yaşar. Ölüm sırası ona da gelir ve sultanın çağrısını reddederek ölüme teslimiyetiyle oyun son bulur.

\section{Yunus Diye Göründüm}

Oyun anlatı çerçevelerinden oluşmaktadır. Ana çerçevesini Anlatıcı ve Ozan'ın konuşmaları, açıklamaları ve tartışmaları oluştururken kuşların arayışı (Simurg'un yolculuğu) ve Yunus'un hikâyesi de iç çerçeveleri oluşturmaktadır.

Anadolu Moğol istilasının yanında kıtlık, kuraklık ve iç savaşla yüz yüzedir. Böyle bir ortamda halkın arasında Hacı Bektaş-ı Veli'nin kerametlerle dolu hikâyesi yayılır. Yunus da köyü için buğday istemeye gider Hacı Bektaş-ı Veli'ye. Yunus'un getirdiği alıç hediyesi Hacı Bektaş-ı Veli'yi memnun 
Karşılaştırmalı Edebiyat Açısından Necip Fazıl'ın Yunus Emre Tiyatrosu ile Nihat Asyalı'nın Yunus Diye Göründüm Tiyatrosunun İncelenmesi

eder ona buğday yerine "soluk" vermeyi teklif eder. Yunus buğdayı tercih eder. Yolda sultanlarını arayan kuşlar ile Yunus'un yolculuğu kesişir. Yunus bilinçsizce aldığı bu karardan rahatsız olurken kuşlar onun bu kararını sorgular. Yunus geri dönerek buğday yerine soluk ister ama Yunus'un kilidi artık Tapduk Emre'dedir. Bir süre bocaladıktan sonra Yunus Tapduk'un tapusuna kul olur. Tapduk'un tapusunda hamken pişip yanan Yunus'un şiirleri dillerde, gönüllerde dolaşmaya başlar, köyüne kadar ulaşır. Yunus'un şiirleri Türkmenler arasında yaygınlaşınca Selçuklu Veziri Muineddin Pervane tedbiren Yunus'u takibe aldırır. Dergâha sorgulayıcılar gönderilir. Sorgulayıcılar Tapduk Emre'den Yunus'u kendilerine teslim etmelerini ister. Tapduk Emre Yunus'u vermez. Onun için dergâhtakilerin her biri Yunus'tur. Yunus dergâhı terk eder. Yunus'u kendine rakip olarak gören siyasi otorite son demlerini yaşamaktadır. Devleti insan için değil, insanı devlet için gören Pervane ile komutan da temsil ettikleri devlet gibi Moğollar tarafından yok edilirler. Yunus'un şiirleriyle oyun biter.

Konu olarak her iki eser de karakter üzerinden geliştirildiği için öncelikle tiyatroların kişiler bakımından incelenmesi önem taşımaktadır.

Necip Fazıl'ın metninde Yunus bir bey oğludur ve Horasan'dan Anadolu'ya gelmektedir. Ölüm korkusu tüm benliğini kapladığı için mezarlığı olmayan köyü (ölümsüzlüğü) aramaktadır. Yazar bunun dışında dış dünyaya ait bir aktarımda bulunmamaktadır. Necip Fazıl, Yunus'u zaman ve mekân ilişkisinden soyutlayarak metafizik bir düzlemde ele almaktadır. İlk mekân varlık ve yokluğun birlikteliğini tanımlayan mezarlıktır. Yunus'un dışındaki karakterler de metafizik özellikler taşımaktadır. Metnin başında yer alan Derviş, Erenler köyündeki Meçhul Adam, Dağdan Gelen Ses, Tapduk Baba gaibden haber veren doğaüstü özellikler taşıyan kişilerdir. Nefsi simgeleyen Bir Kadın Sesi ile Siyahlı Adam da birer karakterden çok simge konumundadır. Yunus oyun boyunca değişimi yaşayandır. Bu değişim iki biçimde gösterir kendini: Dış görünüş ve ruhsal olgunlaşma. Yunus önce bey oğlu kılığındadır, sonra Türkmen daha sonra da derviş. Bu görünüş değişiklikleri dünya malından uzaklaşmasının da simgesi olmuştur. Ruhsal olgunlaşmasını ise şiirleri göstermektedir. Necip Fazıl bu simgeler yoluyla alegorik bir eser oluşturmuştur.

Nihat Asyalı'nın Yunus'u ise hayatta kalmak için mücadele eden cahil bir Türkmen köylüsüdür. Asyalı, Necip Fazıl’ın tersine Yunus'u tarihsel zaman ve mekân ilişkisi içine yerleştirerek, içinde yaşadığı toplumun bir ürünü olarak kurgulamaktadır. Yunus ve tüm Anadolu dönemin siyasal ve kültürel özelliklerini taşımaktadır. Halk Moğol istilası, kıtlık, kuraklık ve iç savaşın yıkımlarından kurtaracak kurtarıcıyı aramaktadır. Köylü, içinde bulunduğu kötü durumdan kendilerini çıkaracak olan kahramanı bulmakta gecikmez. Bütün halk Hacı Bektaş-ı Veli söylencelerine kapılır. Halk için bir umut kapısı olur. Halk ve Yunus ne kadar sıradan ve gerçekse Hacı Bektaş Veli de o kadar yüceltilmiş olağanüstü kılınmış bir kimlik olarak yer alır. Tiyatronun kurgusu gereği sahnelemede Hüthüt, Hacı Bektaş-ı Veli ve Tapduk Emre'yi aynı kişi oynayacaktır. Bu üç kişi de aynı özellikleri taşımaktadır. Bu, 
yol göstericilerin, mürşitlerin yollarının birliğini simgelemektedir. Yunus'un bahtını da döndüren onlardır. Tapduk Emre'ye gelene kadar Yunus bütün bilgilerini yaşam tecrübelerinden alan halkı temsil etmektedir. Anahtarını istemeye gittiğinde Tapduk Emre ona emek vermesini ve bunun için Türkmen Yunus'a bir öğretici gerektiğini söyler. Ama Yunus öğretmeninin olduğunu belirtir. Yunus'un öğretmenleri kıtlık, çekirge, taşkınlar, talanlar, gökyüzünün güneşi, gecelerin yıldızları, gök ekin, bahçelerde açan gül, göklerden dökülen yağmur, çeşmelerden içtiği su, ayağının yürüyüşü ve ellerinin yaptığıdır (Asyalı,2010:146). Yunus'un öğretmenleri dünyevidir. Her iki metinde de Yunuslar farklı sınıfsal özellikler taşısa da dünya nimetlerine olan bağlııkları ortaktır. Her iki oyunda da Yunuslar dünya nimetlerinden vaz geçerek derviş Yunus'a dönüşmektedir.

Konu bakımından karşılaştırma yapılacak olan bu çalışmada her iki eserde de konuyu biçimlendiren üçlü yapıdan söz edilebilir: Ölüm ve ölümsüzlük, dünyevi olanlara meyletme ve uzaklaşma ile yol ve yolculuk figürleri. Bu üçlü yapı birbirini bütünler bir biçimde metnin anlamsal yapısını oluşturmaktadır.

Her iki eserde de ölümsüzlük motifi önemli yer tutmaktadır. Yunus bir bey oğlu olarak ölüm gerçekliğiyle karşılaşınca ölüm karşısındaki güçsüzlüğünü görür ve mezarlığı olmayan köyü aramaya başlar. Bu çaresizliğini şu şekilde ifade eder: "Şu anda, mezarda kefeni bir dilencininkinden farksız bir beyin oğluyum. Bir zaman sırma kaftan giyen bir beyin oğlu" (Kısakürek,2015:15). Ölümsüzlük arayışı bir yol/yolculuk hikâyesine dönüşmektedir. Yunus'un Horasan'dan Anadolu'ya devam eden cismani yolculuğu Erenler Köyü’ne ulaşmasından sonra içsel yolculukla devam edecektir. Ölümsüzlüğü aramak için çıkılan yolculuk kendini bulmaya dönüşecektir. "Mezarlığı olmayan köyü dışında değil, içinde arayacaksın! Diyelim ki onun ismi Erenler köyü... Ona dışındakilerden yol sorma, içindekilerden sor!” (Kısakürek,2015:16). Erenler Köyü’ne ulaştıktan sonra gaibden gelen bir ses onu dağa çağırır.

Yunus'un dağ içinde geçirdiği yolculuk da alegorik engellerle doludur. Bu engeller Yunus'un sorulan soruları cevaplamasıyla ortadan kalkmaktadır. Onun engelleri kendisidir. Kendi engellerini kendine yönelerek (Kendini bilerek) kaldırmaktadır. Engelleri aştıktan sonra mürşidine ulaşacaktır. Mezarlığı olmayan köy arayışı 'gerçek hayat' ve 'erme' ile sonuçlanan bir yolculuğu ifade etmektedir. Yunus, bu yolculuğu “Varlığa ölüm yolundan geçit arıyorum.”(Kısakürek,2015:47) biçiminde tanımlayacaktır.

Nihat Asyalı'nın Yunus'u da başlangıçta hayatın özüne dair hiçbir bilgisi olmayan köylü Yunus'tur. Yaşayabilmekten başka bir amacı yoktur. Onun amacı buğdaydır. Amacını şu şekilde ifade eder: "Yunus: Ne Tanrı'dır benim derdim, ne de uçmağ isterim. Bu dünyadan ver haberi, benim işim bu dünyada. Ben gelmişim tapunuza, buğdayı çok etmek için. Çiğnemişim çiçekleri, buğdayı çok etmek için. Yüreğimi çiğnemişim buğdayı çok etmek için”(Asyalı,2010:147). Oysa Yunus kaderini 
Karşılaştırmalı Edebiyat Açısından Necip Fazıl'ın Yunus Emre Tiyatrosu ile Nihat Asyalı'nın Yunus Diye Göründüm Tiyatrosunun İncelenmesi

yaşayacaktır. Bilgisiz Yunus'un (Miskin Yunus) çıktığı yol bilmeyi gerektirir. “Ölmek gerekse ölmeli, bilmek uğruna ölmeli" (Asyalı,2010:133) der Hüthüt kuşu. Metin bilmek için ölmeyi göze alanların hikâyelerinden oluşmaktadır. Yunus'un hikâyesi de kuşların hikâyesi de bilmek üzerinedir. Bilgi hem Yunus'u hem de kuşları değiştirmektedir. Köylü Yunus buğdaydan vazgeçtiği an değişimi yaşamaya başlar. Dünyevi olana bağlı olarak ölümsüz olunamaz. Dünyayla bağını kopardığı an özüne döner. Yunus'un buğday yolculuğu iç yolcuğuna dönüştüğünde köylü Yunus âşık Yunus'a döner. Yolculuğun niteliği sıkça tekrar edilen şu dörtlükle dile getirilir: "Hararet nardadır, sacda değildir. / Keramet hırkada, tacda değildir. / Her ne arar isen kendinde ara / Kudüs'te, Mekke'de, Hac'da değildir. (144163)" Ölümsüzlüğe götürecek olan yol kendini bilmekten, kendini bulmaktan geçmektedir: "Sakın ol kimsenin gönlünü yıkma / Gerçek erenlerin izinden çıkma. / Eğer insan isen ölmezsin korkma / Aşığı kurt yemez uçta değildir" (Asyalı, 2010:164) "Koro: Bilesin ne olduğun, canı teni bilesin. Yunus: Ten fanidir can ölmez / Çün gitti geri gelmez / Ölür ise ten ölür / Canlar ölesi değil - Çeşmelerden bardağın / Doldurmadan kor isen / Bin yıl orda durursa / Kendi dolası değil” (Asyalı, 2010:164).

Yunus Diye Göründüm metni üç metnin eklemlenişinden oluşmaktadır. Bunlardan birincisi Ozan'la Anlatııı'nın oluşturduğu ana çerçevedir. Diğer ikisi ise ana çerçeve içine yerleştirilen Yunus Emre ve Simurg hikâyeleridir. Bu yolla masal ile gerçek birlikte sunulmuştur. "Masal ne ki, gerçek ne ki/ İzleyelim bu oyunda/ hem masalı hem gerçeği"(Asyalı,2010:123). İç metinlerin en önemli motifi yolculuktur. Klasik edebiyatın en önemli metinlerinden olan Mantık'ut Tayr'la metinlerarası ilişkiler kurularak metne eklemlenmiştir. Bu yol hikâyesiyle konu geliştirilmektedir. Kuşların sultanlarını arayışı kendilerini arayışlarına ve kendilerini bulmalarına dönüşmektedir. Kuşların arayışı ile Yunus'un arayışı paralellik göstermektedir. Her iki yolculuk da maddi olandan başlar: Kuşlar sultanlarının, Yunus buğdayın arayışındadır. Yolculuk hem somut olarak hem de düşsel olarak kolay değildir. Zorluklarla doludur. Kuşlar arasında bu yolculuktan vaz geçenler olurken Yunus da yol ayrımlarında bocalar. Yolculuğunun daha başında kendisine teklif edilen "Buğday mı nefes mi istersin?" seçeneği onun önüne konulan yaşam biçimlerini yansıtmaktadır. Buğday maddi dünyayı simgelerken nefes manevi dünyayı simgelemektedir. Yunus'un buğdayı alıp gitmesi onun daha yolunu belirleyememiş olduğunu göstermektedir. Buğdayla köyüne dönerken kuşların sahnesi ile Yunus'un sahnesi kesişir. Arayışta olanların (kuşlar ve Yunus'un) içsel konuşmaları birbirine karışır. Yunus, Hacı Bektaş Veli'ye geri döner. Buğdayı verip nefes ister. Bu olaydan sonra Yunus'un yolculuğu içsel bir yolculuğa yönelecektir. Bu içsel yolculuktaki rehberi de Tapduk Emre'dir. Bütün zorlukların üstesinden gelerek amacına ulaşır. Campbell'in (2013) Kahramanın Sonsuz Yolculuğu'nda belirttiği anlatı izlencesini Nihat Asyalı da sürdürmektedir.

Her iki eserde de Teknik olarak koro ve solo ögeleri kullanılmaktadır. Koro ve solo, klasik tragedya ve komedyalardan avangard tiyatrolara kadar birçok tiyatro eserinde kullanılagelen bir 
uygulamadır. Tragedyanın kökenlerine inildiğinde koro Diyonizos şenliklerinde Tanrı'nın ona bağlı olan kölelerini simgelemektedir (Nutku, 2001:34). Her iki, tiyatro metninde de koro gaibi, bilinmezi, ötelerin ötesinden gelen sesi ve Yunus'un rehberliğini üstlenmektedir. Koronun sesi Hak dostlarının sesini temsil eder. Bu sesler Yunus'u destekler ya da ona yol gösterir.

\section{Sonuç}

Necip Fazıl, biçimsel olarak tek olay üzerinden klasik bir metin geliştirirken metin içi semboller yoluyla metne derin anlamlar kazandırarak metni güçlendirmiş, alegorik bir metin oluşturmuştur. Nihat Asyalı ise biçimsel olarak farklı anlatım araçlarından yararlanarak çoğulcu bir anlatım geliştirerek özgün bir metin oluşturmayı başarmıştır. Her iki eser de konuyu ele aldıkları motifleri işleyişleri bakımından başarılı ve özgün eserlerdir. Yunus'un hayatı ile ilgili belirsizlikler yazarların kurmaca alanını genişletirken metinlerin oluşmasında her iki yazar da Yunus'un şiirlerini kılavuz olarak kullanırlar. Onun şiirleri olay örgüsünün sınır taşlarını oluşturmaktadır. Her iki metinde de Yunus Emre şiirleri olay örgüsünün şekillenmesinde ustaca kullanılmıştır.

\section{Kaynaklar}

Asyalı, N. (2010). Toplu Oyunları 1: Direniş Üçlemesi: Ateşle Oynayan- Rab Şeytan'a Dedi ki Yunus Diye Göründüm -.Istanbul: Mitos Boyut Yayınları, 2010.

Aytaç, G. (2009). Karşılaştırmalı Edebiyat Bilimi. İstanbul: Say Yayınları.

Campbell, J. (2013). Kahramanın Sonsuz Yolculuğu. İstanbul: Kabalcı Yayınevi.

Gevrek, A. (2012). Türk Tiyatrosunda Yunus Emre. İstanbul:Toplumsal Yayıncılık.

Göbenli, M. (2005). Direnmenin Estetiği'ne Güven-Karşılaştırmalı Edebiyat Bağlamında Peter Weiss ve Vedat Türkali-. İstanbul: Donkişot Güncel Yayınlar.

Kefeli, E. (2000). Karşılaştırmalı Edebiyat incelemeleri. İstanbul: Kitabevi.

Kısakürek, N. F. (2015). Yunus Emre. İstanbul: Büyük Doğu Yayınları.

Nutku, Ö. (2011). Dram Sanatı-Tiyatroya giriş-. İstanbul: Kabalcı Yayınevi, 2001.

Yıldııı, A. ve Şimşek, H. (2011). Sosyal Bilimlerde Nitel Araştırma Yöntemleri. Ankara: Seçkin Yayınevi, 2011. 